
Bahamian University Students

\author{
Elizabeth J. Williams \\ William J. Fielding \\ (iD) 0000-0001-5433-9673 \\ Virginia C. Ballance \\ (iD) 0000-0003-1067-8205
}

\title{
University of The Bahamas
}

\begin{abstract}
This study investigates the mental health of victims of sexual abuse, particularly rape, in college student populations. The study identifies the connection between sexual abuse/rape and elevated scores of mental health. It indicates that even with other stressful events occurring in the lives of respondents, sexual abuse/rape has a detrimental effect on the mental health of both males and females. A death in the family was the most commonly reported stressful event for males and females, and females were more likely than males to have suffered from a sexual attack. Early negative experiences of sexual intercourse can apparently have long lasting negative effects on the victim's mental health. These findings require society to look beyond the physical consequences of sexual abuse and rape to ensure that the long-term mental health of victims, both male and female children and adults, is not overlooked.
\end{abstract}

\section{Dedication}

Dr. Elizabeth Williams joined The College of The Bahamas on September 1, 2004 as a lecturer in the Critical Care Nursing programme. Her doctoral dissertation was entitled The Influence of Knowledge and Self-efficacy on Bahamian Women's Adherence to a Hypertensive Medication Regime (2011) which recognized the importance of hypertension in our community. Her gentle manner made her a favourite with students, who voted her as the best lecturer in the School of Nursing and Allied Health Professions. Her love of research was evident in the way she taught the higher-level research classes and her enthusiasm and dedication made her a popular teacher of research. She encouraged her students to study important topics, and this last research project of hers is a testament to her willingness to address "hard" issues which impact women's health.

This paper, dedicated to the life and memory of Dr. Elizabeth Williams, is the project that she was working on before her untimely death. The completion of this project would not have been possible without the exceptional support of the co-authors. I hope that the findings of this study will fill an important gap in our knowledge of mental health in The Bahamas and add to the current body of knowledge.

Ingrid Mobley, Ph.D., ARNP

https://doi.org/10.15362/ijbs.v27i0.395 @ W W. Fielding \& V. Ballance, 2021.

Journal compilation @International Journal of Bahamian Studies, 2021. 


\section{Introduction}

Although there have been many studies done in The Bahamas on risky sexual behaviours (Deveaux \& Rolle, 2016), other aspects of sexual abuse and rape appear to have been less studied. Gender-based violence in The Bahamas is a national concern. The relatively high incidence of rape has been recognized through the Bahamas National Task Force for Gender-based Violence report (2015). Although women in particular are worried about being victims of rape, their fear bears no relationship to the reported crime figures on rape. This suggests that even a singular event causes great worry, and/or they presume that rape is more common than the official figures suggest, a position that is confirmed by both Aranha (2016) and Bethel and Fielding (2020). The study by Bethel and Fielding (2020) on college students in The
Bahamas highlighted that many victims of rape are unaware that they have been raped and that females can engage in unwanted sexual intercourse due to being afraid of their intimate partner. Bethel and Fielding (2020) also found that men can be forceful in getting their intimate partners to participate in sexual intercourse, even when it is unwanted. They also found that college students still subscribe to myths with regard to sexual intercourse, such as strangers are most likely to rape a woman.

Another rape related myth that persists in The Bahamas is that only females can be victims of rape (Rolle, 2020). Unpublished statistics provided by the Royal Bahamas Police Force (see Table 1) confirm that male rape occurs, although it is accepted that male and female rape is under-reported (Bethel \& Fielding, 2020).

\section{Table 1}

Number of Rapes, by Sex, Reported to the Royal Bahamas Police Force

\begin{tabular}{cccc}
\hline Year & $\begin{array}{c}\text { Male } \\
n=\end{array}$ & $\begin{array}{c}\text { Female } \\
n=\end{array}$ & $\begin{array}{c}\text { Males raped } \\
\%\end{array}$ \\
\hline 2017 & 0 & 56 & $0 \%$ \\
2018 & 4 & 56 & $6.7 \%$ \\
2019 & 3 & 44 & $6.4 \%$ \\
\hline
\end{tabular}

Note. Figures subject to change, Royal Bahamas Police Force (unpublished).

Bethel and Fielding (2020) found in their study that none of the men who were raped reported their victimization, so they would be unlikely to benefit from any formal support to cope with their trauma. Even though male rape is less common than female rape, it should not be overlooked because it may be even more traumatic for men than women; Musevenzi and Musevenzi (2018) illustrate this in their study of men in Zimbabwe who were raped and fear being seen as feminine and no longer being masculine. African children's experiences of physical violence and sexual violence have been related to risky sexual behaviour and mental health concerns (Smith et al., 2020). This demonstrates that adverse sexual experiences in both boys and girls can be detrimental to their mental health. It has also been demonstrated in the United States that forced sexual intercourse has detrimental effects beyond physical and mental trauma, such as negative academic outcomes - effects that can be life-long and have implications for the development of a country (Rees \& Sabia, 2013). In the United States, the experience of rape was linked to 
poorer mental health among women (Potter et al., 2020) and may result in depression and anxiety (Nickerson et al., 2013). The longterm effects of child sexual abuse on the mental health of adult females include anger, depression, and sexual problems (Hailes et al., 2019).

In the Caribbean, Pilgrim and Blum (2012) identified a number of environmental factors, including peers who engaged in violence, as having negative influences on mental health; the importance of mental health issues has resulted in the Caribbean medical literature devoting special issues to the topic (Barton, 2012). The 2017 World Health Organization report on mental health indicates that, in The Bahamas, many of its indicators have not been reported on, and there appears to be a lack of mental health programmes (World Health Organization, 2017).

The literature on violence and rape often focusses on university students living on residential campuses. However, the study population in this research project, although university-aged students, typically live in domestic settings, not student accommodation, so their experiences can be expected to reflect those of non-resident campus populations, such as that of students attending community colleges (Voth Schrag \& Edmond, 2018; Potter et al., 2020). Therefore, the responses of participants should not be assumed to reflect sexual experiences in a specific place.

The purpose of this cross-sectional study was to focus on the mental health of victims of rape or sexual abuse in college students. It aimed to identify links, if any, between being a victim of rape and the victim's mental health. It also aimed to assess the impact of other traumatic events to put the event of rape in a wider context.

\section{Method}

An Internet-based survey was devised that incorporated some of the questions asked by Bethel and Fielding (2020). These included standard items on respondents' demographics as well as questions about their lifetime experiences of sexual intercourse and their attitudes towards rape. The questionnaire also included 19 aspects relating to the mental health of the respondent. These aspects included statements such as, "I wish I were somebody else," "I feel like I am inferior to others," and "I blame myself for being sexually abused." The writing authors believe that these questions may have been drawn from a number of stress/trauma related scales (such as Amirkhan, 1990; Sharma, 2018; Swahnberg \& Wijma, 2003) and possibly reworded to be culturally appropriate for a Bahamian student population. The scale was a Likert response scale with a frequency response scale from 1 (never) to 5 (always), so the minimum score in this scale was 19 and the maximum score 95. In this study, the Cronbach's $\alpha$ for the scale was .94. The survey included additional questions about events in the life of participants that may have been stressful, such as a death in the family or being a victim of crime.

The target population was enrolled collegelevel students in The Bahamas. Students from a nursing research class used their social media contacts to recruit students, with credit being given to students for getting students to participate in the survey via a link to the SurveyMonkey ${ }^{\mathrm{TM}}$ questionnaire. Although such a student population does not reflect the wider population, its members are drawn from across the country, particularly New Providence, so it predominately represents an urban population. The students reflect a range of economic backgrounds, and many receive financial aid from the government to attend university. The study was approved by the 
Institutional Review Board of University of The Bahamas.

\section{Findings}

There were 1,240 starts in the survey. One person who entered the survey declined to participate. After cleaning the data so that only respondents who were members of the target population were included, 865 respondents were retained. Not all surveys were completed, so this is the maximum number of respondents. Two respondents gave their sex as "other" and this group was omitted due the small number of responses. Of the remainder, most respondents were female ( $82.1 \%$ of $N=860)$. Although most of the results are presented disaggregated by sex, in the case of males, in some cases the number of responses was small, so we then just present the results from the female participants. The modal age group was 21-24 years $(42.3 \%)$. Overall, $84.4 \%$ of participants had participated in sexual intercourse; this percentage was similar for both sexes $\left(\chi^{2}=\right.$ $.54, d f=1, N=858, p=.816)$. However, females were more likely than males to be participating in stable relationships (sexually involved with the same partner for 12 months or more): $59.1 \%$ compared with $47.3 \%$ of males $\left(\chi^{2}=7.03, d f=1, N=853, p=.008\right)$.

\section{Context of the Fear of Rape}

Fear of rape is one of many anxieties, so respondents were asked to rank their concerns; they were more concerned about crimes against the person than property (see Table 2). The fear of being a victim of crime was dissimilar between the sexes. Table 2 shows that rape is the crime most feared by women, whereas men are most fearful of being shot. As demonstrated by Bethel and Fielding (2020), the fear of crime does not reflect the statistical occurrence of crimes reported by the Royal Bahamas Police Force (2020).

Table 2

Mean Ranked Fear of Being a Victim of Selected Crimes

\begin{tabular}{lccc}
\hline \multicolumn{1}{c}{ Crime, mean rank } & Male & Female & \multirow{2}{*}{$\begin{array}{c}\text { N } \\
\text { N }\end{array}$} \\
& $M$ & $M$ & \\
\hline Being raped & 4.2 & 2.6 & $<.001$ \\
Being shot & 3.0 & 3.6 & $<.001$ \\
Being sexually abused & 5.3 & 3.8 & $<.001$ \\
Being held up and robbed & 3.5 & 4.2 & $<.001$ \\
Being physically attacked by another & 4.2 & 4.3 & .47 \\
Having your home broken into & 4.0 & 4.7 & $<.001$ \\
Having your car stolen & 5.2 & 5.9 & $<.001$ \\
Having something stolen from your car & 6.6 & 6.8 & .081 \\
\hline
\end{tabular}

Note. $1=$ most fearful, 8 least fearful; $p$ values from $t$-test.

\section{Attitudes Toward Rape}

Females were more aware than men of the importance of consent with regard to sexual intercourse, and men were more likely to view rape as requiring physical resistance by 
the victim to make the unwanted sex rape (see Table 3). Close to $40 \%$ of both males and females agreed that rape cannot occur within marriage; this indicates the considerable disagreement on this topic in a society where the law recognizes rape only outside of marriage, as demonstrated in debates on martial rape (Benjamin \& LeGrand, 2012). Some respondents in this study indicated that they may have been sexually abused by their husbands. Although this study did not ask about marital status directly, when we grouped respondents who were aged over 30 and in long-term relationships (one year or more) together with those who were married, $7.2 \%$ of these 69 females reported having sex against their will with their partner in their most recent sexual encounter.

Table 3

Percentage of Respondents, Within Sex, Agreeing to Various Aspects of Rape

\begin{tabular}{lccc}
\hline \multicolumn{1}{c}{ Aspects of rape } & Male & Female & $X^{2}$ \\
\hline $\begin{array}{l}\text { Rape occurs when one of those engaged in the sexual intercourse } \\
\text { did not consent }\end{array}$ & 92.1 & 96.3 & .019 \\
$\begin{array}{l}\text { Rape occurs when one of those engaged in sexual intercourse } \\
\text { consents due to threats or fear of bodily harm from the other person }\end{array}$ & 86.8 & 85.3 & .483 \\
A married couple cannot rape each other & 39.6 & 43.8 & .221 \\
Rape only occurs when the victim tries to fight off their attacker & 15.9 & 9.7 & .011 \\
Only females can be raped & 4.0 & 1.3 & .085 \\
\hline
\end{tabular}

\section{Participation in Sexual Intercourse}

Similar percentages of males $(16.2 \%)$ and females $(15.5 \%)$ had never participated in sexual intercourse $\left(\chi^{2}=.054, \mathrm{df}=1, N=858\right.$, $p=.82$ ). Males tended to engage in sexual intercourse at an earlier age than females (see Figure 1). We also note that $30.7 \%$ of males and $15.7 \%$ of females who had participated in sexual intercourse did so before age 16 .

\section{Figure 1}

\section{Percentage of Males and Females by Age at First Experience of Sexual Intercourse}

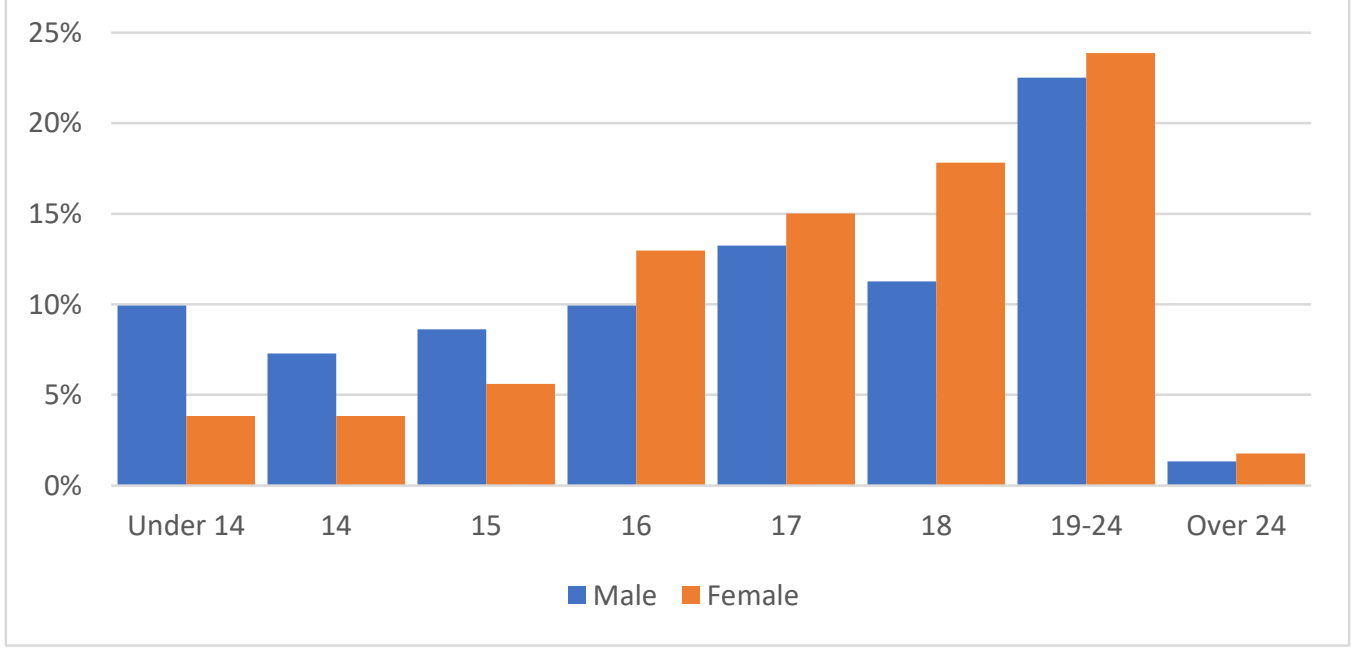


Males and females reported having different experiences of their first participation in sexual intercourse. Females were more likely than males to agree that their first experience of sexual intercourse was not agreeable and, on reflection, was abuse (see Table 4).
However, it should be noted that both males and females felt that they had been abused when they first had sexual intercourse and both males and females had various degrees of negative experiences.

\section{Table 4}

Percentage of Respondents Agreeing to Various Aspects of their First Experience of Sexual Intercourse

\begin{tabular}{lccc}
\hline \multicolumn{1}{c}{ First experience of sexual intercourse } & Male & Female & $X^{2}$ \\
\hline & $\%$ & $\%$ & $p=$ \\
\hline I had sexual intercourse against my will & 4.8 & 12.6 & .048 \\
I found the experience enjoyable & 73.6 & 41 & $<.001$ \\
I did not enjoy it but my partner did & 13.6 & 38.1 & $<.001$ \\
I clearly agreed to have sexual intercourse & 93.5 & 78.3 & .001 \\
Afterwards, I wished I had not agreed to the sexual & 9.6 & 37.0 & $<.001$ \\
intercourse & 76.6 & 88.0 & .017 \\
I knew the person well with whom I had sexual intercourse & 80.6 & 45.8 & $<.001$ \\
Afterwards, I wanted to repeat the experience & 5.6 & 14.1 & .009 \\
$\begin{array}{l}\text { On reflection, I feel that I was sexually abused when I first } \\
\text { had sexual intercourse }\end{array}$ & & &
\end{tabular}

Although clear consent prior to having sex was given by most males and females, respondents indicated that they sometimes were unable to give consent or gave consent out of fear of their partner (see Table 5). Several differences in the experiences surrounding sexual intercourse were reported by males and females as seen in Table 5 . Females reported being hurt by their partners, $23.6 \%$ of females had been hit by their intimate partners. Participating in sexual intercourse under circumstances of fear or incapacitation invalidates the consent and makes it rape. Table 5 also indicates that $6.7 \%$ of males raped females due to having sex with underage partners.
In their most recent experience of sexual intercourse, there were no statistically significant differences between the sexes in their attitudes towards their experience (see Table 6). This is a marked contrast to their recollections of their first experience of sexual intercourse as seen in Table 4.

Significantly more female than male respondents reported having sexual partners of both sexes $\left(\chi^{2}=564.9, d f=2, N=674, p\right.$ $<.001$; see Table 7). This finding is consistent with Bethel and Fielding (2020) and broadly in line with female choice of partner in the United States (Tansill et al., 2012). 
Table 5

Percentage of Respondents Agreeing to Various Aspects of their Experiences of Sexual Intercourse

\begin{tabular}{|c|c|c|c|}
\hline Aspect & Male & Female & $x^{2}$ \\
\hline & $\%$ & $\%$ & $p=$ \\
\hline $\begin{array}{l}\text { Do you always give clear consent (verbal or non-verbal permission) } \\
\text { before having sexual intercourse? }\end{array}$ & 79.8 & 81 & .61 \\
\hline $\begin{array}{l}\text { Have you ever had sexual intercourse with an individual because } \\
\text { you were afraid of them? }\end{array}$ & 1.7 & 15 & $<.001$ \\
\hline $\begin{array}{l}\text { Have you ever had sexual intercourse when you were physically or } \\
\text { mentally unable to give consent? (e.g. drunk or high) }\end{array}$ & 24.4 & 25.6 & .032 \\
\hline $\begin{array}{l}\text { Have you ever had sexual intercourse when your partner was } \\
\text { physically or mentally unable to give consent? (e.g. drunk or high) }\end{array}$ & 18.5 & 15.5 & .44 \\
\hline $\begin{array}{l}\text { Have you ever had sexual intercourse with a person under the age } \\
\text { of } 16 \text { ? }\end{array}$ & 6.7 & 1.4 & $<.001$ \\
\hline Have you been hit or physically hurt by your intimate partner? & 10.1 & 23.6 & $<.001$ \\
\hline
\end{tabular}

Note. Options include Not sure except when marked §.

\section{Table 6}

Percentage of Respondents Agreeing to Various Aspects of their Most Recent Experience of Sexual Intercourse

\begin{tabular}{lccc}
\hline \multicolumn{1}{c}{ Agreeing to } & Male & Female & $X^{2}$ \\
\hline & $\%$ & $\%$ & $p=$ \\
\hline I had sexual intercourse against my will & 4.1 & 5.7 & .273 \\
I found the experience enjoyable & 87.9 & 82.4 & .163 \\
I did not enjoy it but my partner did & 11.3 & 12.5 & .197 \\
I clearly agreed to have sexual intercourse & 96.8 & 91.0 & .072 \\
Afterwards, I wished I had not agreed to the sexual intercourse & 7.4 & 11.4 & .055 \\
I knew the person well with whom I had sexual intercourse & 91.0 & 92.0 & .63 \\
Afterwards, I wanted to repeat the experience & 81.8 & 80.3 & .202 \\
On reflection, I feel that I was sexually abused when I had sexual & 2.5 & 3.7 & .299 \\
intercourse & & & \\
\hline
\end{tabular}

\section{Table 7}

Choice Sex of Intimate Partner by Sex of Respondent.

\begin{tabular}{lcc}
\hline Sex of those with whom respondents had sexual intercourse & Male \% & Female \% \\
\hline Only male & 4.2 & 87.0 \\
Only female & 89.2 & 0.7 \\
Both male and female & 6.7 & 12.3 \\
\hline
\end{tabular}


Females were more likely than males to report being a victim of physical violence from their intimate partner: $23.6 \%$ of females and $10.1 \%$ of males $\left(\chi^{2}=10.8, d f=1, N=\right.$ $673, p=.001)$. A larger percentage of female than male participants $(47.9 \%$ of 368 responses, compared to $33.1 \%$ of 103 responses; $\chi 2=7.15, d f=1, N=471, \mathrm{p}=$ $.007)$ had participated in sexual intercourse against their will; in the case of females who had engaged in unwanted sexual intercourse, $27.8 \%$ had done so in the last month. Similarly, $23.7 \%$ of 536 females and $7 \%$ of 113 males admitted to having been raped at least once $\left(\chi^{2}=16.2, d f=4, N=649, p=\right.$ $.003)$. Only one of 11 male respondents obtained medical help for physical reasons following the sexual abuse. In the case of females, $5.6 \%$ of 88 respondents sought help for mental health reasons after being sexually abused, and $4.3 \%$ sought help for physical reasons following the abuse. Of the 24 males who had suffered sexual abuse/rape, 58.3\% agreed that it had affected their mental health; in the case of females, $81.7 \%$ of 241 respondents agreed that it has affected their mental health.

\section{Events Impacting Mental Health}

Various events in our lives can have negative impacts upon us and some of these events were included in the study. Here we consider events that respondents thought had impacted their mental health. Females were more likely than males to have suffered at least one event in Table 8 that they thought negatively affected their mental health in the previous 10 years: $54.8 \%$ of females and $40.3 \%$ of males $\left(\chi^{2}=10.77, d f=1, N=856, p=.001\right)$. The most commonly reported stressful event related to a death of a friend or family member. However, the negative impact associated with being a victim of a sexual attack was clearly different for males and females. Overall, it was apparent that females were more likely than males to report events in their lives that affected their mental health $\left(\chi^{2}=46.6, d f=1, N=860, p<.001\right.$, see Table $8)$. The other category included natural disasters, such as Hurricane Dorian and the Covid-19 pandemic, and life events, such as ending a relationship (break-up) and taking university examinations.

\section{Table 8}

Percentage of Respondents Reporting Events that Had Negatively Affected Their Mental Health

\begin{tabular}{lccc}
\hline \multicolumn{1}{c}{ Negative event } & Male & Female & \\
\hline A death of a friend/family member & $\%$ & $\%$ & $p=$ \\
Victim of bullying & 27.9 & 29.6 & .68 \\
Victim of a sexual attack & 7.1 & 10.9 & .16 \\
Victim of a physical attack & 2.6 & 10.8 & .002 \\
Victim of property crime & 3.2 & 6.9 & .087 \\
Other & 5.2 & 5.1 & .96 \\
$N$ & 9.7 & 18.1 & .006 \\
\hline
\end{tabular}

Note. Multiple answers allowed. 
In Table 9, we only focused on females being victims of rape due to the relatively small number of males who were victims of rape. Being a victim of rape is associated with elevated chances of experiencing other events that respondents considered detrimental to their mental health $\left(\chi^{2}=55.5\right.$, $d f=16, N=350, p<.001$, see Table 9). Using the responses of participants who had never been victims of rape as a benchmark, it can be appreciated that as the occurrence of rape increases, so do other stressful events, or the reverse may be the case.

Being a victim of a sexual attack resulted in the largest differences between the mental health scores of victims and non-victims of any of the negative events in Table 9 (victims, $M=48.5$, non-victims, $M=35.9$, $t(630)=7.48, p<.001)$. Analysis of covariance, taking into account the occurrence of the events in Table 9, resulted in adjusted means (victims, $M=45.9$, nonvictims, $M=36.3, p<.001)$.

\section{Table 9}

Percentage of Female Respondents Reporting Being a Victim of Rape and Also Experiencing Events that Had Negatively Affected Their Mental Health, Percentages Within Victim of Rape

\begin{tabular}{lcccccc}
\hline Victim of rape & $\begin{array}{c}\text { A death of a } \\
\text { friend/ family } \\
\text { member }\end{array}$ & $\begin{array}{c}\text { Victim of } \\
\text { property } \\
\text { crime }\end{array}$ & $\begin{array}{c}\text { Victim of a } \\
\text { physical } \\
\text { attack }\end{array}$ & $\begin{array}{c}\text { Victim of a } \\
\text { sexual attack }\end{array}$ & $\begin{array}{c}\text { Victim of } \\
\text { bullying }\end{array}$ & \\
\hline No, never & $\%$ & $\%$ & $\%$ & $\%$ & $\%$ & $N$ \\
Only once & 27.9 & 4.9 & 4.9 & 4.2 & 8.1 & 409 \\
Sometimes & 26.9 & 10.6 & 10.6 & 33.3 & 12.1 & 66 \\
Often & 33.3 & 4.4 & 15.6 & 40.0 & 15.6 & 45 \\
Frequently & 50.0 & 0.3 & 41.7 & 75.0 & 33.3 & 12 \\
\hline
\end{tabular}

\section{Mental Health Scores}

The 19 questions on mental health were used to calculate a mental health score, with lower scores indicative of better mental health than higher scores. The minimum score in this scale was 19 and the maximum score 95 . The overall mean mental health score was 37.3 $(S E=.54)$. However, females had a higher mental health score than males (females, $M=$ $37.9, S E=.6$, males, $M=34.3, S E=1.26, t=$ $-2.57, d f=627, p=.01$ ). This result is consistent with other literature from the Caribbean (Pilgrim \& Blum, 2012).
It would appear that there may be long lasting effects on the mental health of females who felt abused when they first participated in sexual intercourse, as those who felt sexually abused when first initiated into sex had a higher mean mental health score than those who did not feel abused (see Table 10). This would suggest that even though other events had a negative impact on the mental health of female participants, it was still possible to detect the residual negative effect of their first sexual encounter. 
Table 10

\begin{tabular}{|c|c|c|c|}
\hline $\begin{array}{l}\text { Sexually abused at } \\
\text { first sexual } \\
\text { intercourse }\end{array}$ & $M$ & $S E$ & $p=$ \\
\hline 1 Strongly agree & 44.8 & 2.05 & \\
\hline 2 & 46.2 & 6.3 & \\
\hline 3 Cannot say & 39.9 & 1.86 & $<.001$ \\
\hline 4 & 40.2 & 2.54 & \\
\hline 5 Strongly disagree & 36.2 & .65 & \\
\hline
\end{tabular}

Note. $p$ value from analysis of variance.

Females who had experienced unwanted sexual intercourse reported having higher mental health concerns the more frequently they had had unwanted sex (see Table 11); therefore, within the group of females participating in unwanted sex, the repetition of the event is linked with a higher mean mental health score. In the case of females, the more frequently they had had sex against their will, the higher their mental health score: $r=.16(p<.001)$.

Table 11

Mean Mental Health Score and Lifetime Experience of Unwanted Sex of Female Respondents

\begin{tabular}{llll}
\hline $\begin{array}{l}\text { Had sex against } \\
\text { your will: }\end{array}$ & $M$ & $S E$ & $p=$ \\
\hline Only once & 37.4 & .89 & \\
A few times & 41.6 & 1.44 & \\
Often & 46.4 & 5.14 & .001 \\
Frequently & 49.8 & 6.09 & \\
\hline
\end{tabular}

Note. $p$ value from analysis of variance.

$N=324$

In the case of their most recent sexual encounter, those females who felt that they had been abused had higher mental health scores than those who did not feel abused (Kruskal-Wallis $\mathrm{H}=12.6, d f=4, p=.013$ ). Also, having been hit by their intimate partner was associated with a higher mean mental health score $(t=3.81, d f=629, p<$ $.001)$.

In the case of rape, both males and females had higher mean mental health scores, even when the scores were adjusted for other negative events in their lives, other than sexual abuse (see Table 12). Although the mean mental health score for males who had been raped sometimes has a high standard error due to the small sample size, the fact that it is the largest mean in the table may still indicate the detrimental effect rape has on males. This is more evident when we appreciate that, overall, males had a lower mental health score than females (males, 34.3, $S E=1.26$, females, 37.9, $S E=.60)$, a mean difference of 3.6 .

Although the mental health scores between respondents who had had sexual relations with others of the same sex were not statistically different (ANOVA, $F(2,622)=$ $1.21, p=.3$ ), the interaction between sex of respondent and sexual partner $(F(2,622)=$ 2.2, $p=.112$ ) was suggestive of greater trauma associated with respondents who participated exclusively in non-heterosexual sex (see Table 13). The relatively small sample size of the number of respondents who reported sexual intercourse with both sexes or the same sex as themselves may account for the lack of statistical significance.

Female study participants who had been sexually abused indicated that the most likely victimizers were people known to them, in particular current or ex-boyfriends or friends. However, it should be noted that relatives and those with trusted access to the victim were reported as victimizers by about a quarter of the abused respondents. Relatively few females had been victimized by strangers (see Table 14). This finding is consistent with Bethel and Fielding (2020) and in line with a study from the United States (Brooks, 2001). 
Table 12

Mean Mental Health Score and Respondent Lifetime Experience of Rape, by Sex of Respondent

\begin{tabular}{lrrccc}
\hline Sex & Raped & $M$ & $S E$ & $N$ & $p=$ \\
\hline \multirow{3}{*}{ Male } & Never & 33.6 & 1.18 & 101 & \\
& Only once & 35.5 & 5.98 & 4 & .003 \\
& Sometimes & 58.4 & 6.96 & 3 & \\
\multirow{3}{*}{ Female } & Never & 36.2 & .66 & 389 & \\
& Only once & 40.3 & 1.67 & 62 & \\
& Sometimes & 43.1 & 1.99 & 44 & .007 \\
& Often & 46.6 & 4.06 & 11 & \\
& Frequently & 40.6 & 6.35 & 4 &
\end{tabular}

Note: Means adjusted for occurrence of negative events in the lives of the respondents in Table 7, excluding sexual abuse. $p$ values from analysis of variance.

Table 13

Mean Mental Scores of Respondents, by Their Sex and the Sex of Their Intimate Partners

\begin{tabular}{lcc}
\hline Sex of those with whom respondents had sexual intercourse & Male & Female \\
\hline & $M$ & $M$ \\
\hline Only male & 49.6 & 37.3 \\
Only female & 33.0 & 38.7 \\
Both male and female & 40.6 & 42.3
\end{tabular}

Table 14

Association Between the Victimizer and Female Sex Abuse Victim

\begin{tabular}{lcc}
\hline Female participants having had sex against their will with: & \% reports & Group \% \\
\hline Boyfriend & 35.9 \\
Best friend & 0.5 \\
Boyfriend (first time) & 0.5 \\
Boyfriend and uncle & 0.5 \\
Boyfriend, brother & 0.5 \\
Boyfriend/Guy I had frequent sex with & 0.5 \\
Boyfriends, cousins, uncles & 0.5 \\
Intimate partner/ friends with benefits & 0.5 \\
Ex-boyfriend & 4.6 \\
First ex-boyfriend & 0.5 \\
Now ex-boyfriend & 0.5 \\
Date & 1.5 \\
\hline & 91.0 \\
\hline Friend & 1.8 \\
Family friend & 3.1 \\
Friend, brother & 1.0 \\
\end{tabular}




\begin{tabular}{|c|c|c|}
\hline Female participants having had sex against their will with: & $\%$ reports & Group \% \\
\hline "Friend" and boyfriend & 1.0 & \\
\hline "Friend" & 0.5 & \\
\hline "Trusted" friend & 0.5 & \\
\hline Friend, we were never actually together, we never make it official & 0.5 & \\
\hline Friend/Neighbor & 0.5 & \\
\hline A guy who was my friend but isn't my friend anymore & 0.5 & \\
\hline Ex Best friend & 0.5 & \\
\hline Fiancé and Old Friend & 0.5 & \\
\hline $\begin{array}{l}\text { Not intercourse, but assaulted or touched against my will by someone I } \\
\text { was friends with }\end{array}$ & 0.5 & 20 \\
\hline Group $n=$ & 39 & \\
\hline Husband & 4.6 & \\
\hline Uncle & 1.5 & \\
\hline Uncle, close friend at former high school & 0.5 & \\
\hline My children [sic] daddy & 0.5 & \\
\hline Father & 0.5 & \\
\hline Stepfather & 2.6 & \\
\hline Godfather & 0.5 & \\
\hline Brother & 2.6 & \\
\hline Cousin & 6.7 & \\
\hline Cousin (male) & 1.0 & \\
\hline Cousin and girl in primary school & 0.5 & \\
\hline Rape and Sexual Abuse- Male cousin & 0.5 & \\
\hline Relatives & 0.5 & \\
\hline God brothers & 0.5 & 23.1 \\
\hline Group $n=$ & 45 & \\
\hline Neighbour & 1.5 & \\
\hline A situationship I was in [verbatim, not clear to authors] & 0.5 & \\
\hline Babysitters [sic] son, uncle, brother & 0.5 & \\
\hline Can't say & 0.5 & \\
\hline Co worker & 0.5 & \\
\hline Da dog outside & 0.5 & \\
\hline Ex friend's uncle & 0.5 & \\
\hline Just sexually assaulted/abused & 0.5 & \\
\hline $\begin{array}{l}\text { Sexually abused never raped. First time it was my cousin. Second a } \\
\text { police officer. Third a priest. }\end{array}$ & 0.5 & \\
\hline Older neighbour & 0.5 & \\
\hline The entire world, police and family & 0.5 & 6.7 \\
\hline Group $n=$ & 13 & \\
\hline Stranger & 3.1 & \\
\hline Stranger I met once prior & 0.5 & 3.6 \\
\hline Group $n=$ & 7 & \\
\hline$N=$ & 195 & \\
\hline
\end{tabular}




\section{Discussion}

In considering the results, we should be aware that the target population was collegelevel students, not the wider population, so, although the study provides useful insights with regard to sexual experiences and mental health, it may not reflect what occurs in the wider and more diverse population of The Bahamas, particularly with respect to older people. Notwithstanding these limitations, this study goes some way to contributing to the need identified in the Strategic Plan to Address Gender-Based Violence (Bahamas National Task Force for Gender-based Violence, 2015) to undertake further research on gender-based violence in The Bahamas.

Although interpersonal violence has many negative physical impacts on victims (Campbell, 2002) that cannot be separated from mental trauma, this study only aimed to identify possible links between the mental health of Bahamian college students and their negative experiences of sexual intercourse; also, it allows additional linkages to be made, as it considers other traumas that may influence mental health. Although this is a limitation of the study, it does help to complement the study on physical trauma in The Bahamas by Burnett-Garraway (2001).

The methodology of this study is not necessarily the most appropriate to identify linkages between negative sexual experiences and mental health, but in the absence of a longitudinal study, which could have identified the changes in mental health over time, this study may still be useful in providing preliminary information on how negative sexual experiences affect mental health.

The study findings are similar to those reported by researchers in the United States (Voth Schrag \& Edmond, 2018) and by
Bethel and Fielding (2020), who reported on the life-time sexual experiences of college students in The Bahamas. The fear of rape was again found to be the crime of greatest concern to females, even though, according to police statistics, it is not a commonly reported crime (Bethel \& Fielding, 2020). The current study confirms that sexual intercourse is an activity that is not without risk of violence, particularly for females, and some females, even if not admitting to being raped, clearly agreed to participate in sexual intercourse out of fear. This may help to explain the fear that females have of rape, even if they do not feel that they have been raped. The violence to which they are subjected by their intimate partner may ultimately be manifested by rape. Therefore, violence appears to be a normative aspect of female life. The fact that about $25 \%$ of the female participants had unwanted sex in the previous month indicates that unwanted encounters are not uncommon. As Bethel and Fielding (2020) found, circumstances such as this increase the percentage of individuals who are legally raped beyond the percentage of people who admit to being raped.

Although it is easy to focus on female rape and abuse, this study confirms the results of Bethel and Fielding (2020) and unpublished data provided by the Royal Bahamas Police Force (see Table 1) that males are also subjected to rape. As indicated by others, for example, Musevenzi and Musevenzi (2018), rape can be even more traumatic for male victims than for female victims due to its associated stigma. Additionally, as has been reported elsewhere, for example, Pakistan (Ali et al., 2013), it is not unusual for victims to be unwilling to seek help. Consequently, this suggests that there should be increased greater concern for appreciating that only females are victims of rape and need help. 
Although the first sexual experience of females was less satisfactory than for males, it is apparent that the most recent sexual encounters of males and females were experienced with equal approval, even though some respondents may have felt abused. The study confirmed that persons known to the victim were the most likely group to inflict sexual abuse/rape. Family members accounted for about $25 \%$ of victimizers identified by respondents (Table 14), indicating that family members used their privileged position in the family to victimize others. This helps to explain why sexual abuse/rape is under reported, as it is concealed behind the walls of the home, which hinders reporting and investigation of cases. Dating violence in adolescent women has been demonstrated to be associated with greater mental health concerns (Hébert et al., 2008).

Dating violence may be what is being described in Table 14, where boyfriends, etc. were reported as being commonly responsible for the violence inflicted upon our study respondents, a figure consistent with the range reported by Bergen and Barnhill (2006). Beyond dating violence, we should note that in the United States, $14 \%$ of married women have reported being raped by their husbands (Brooks, 2001). Therefore, given the expected small number of married females in a college population, the fact that $7.2 \%$ of older female respondents reported being victimized by their husband/long-term partner is noteworthy, and the occurrence of martial rape requires further study in The Bahamas. It is apparent that intimate partners can be violent towards those with whom they have relationships, and this violence is also associated with increased mental health scores. Consequently, various negative aspects of imitate relationships, violence, sexual abuse, and rape can contribute to higher mental health scores.
As might have been expected, respondents had experienced a number of events that they felt had negatively affected their mental health; the most common of these was a death of someone whom they knew. Respondents who had reported being raped were also more likely to have suffered other events in their lives that had negative impacts on their mental health. As noted in Norway, childhood experiences of violence increase the risk of these children being victimized as adults and increase their risk of suffering from mental health concerns (Thoresen et al., 2015). This study cannot explain why this might be, but it may be associated with persons who have less coping capability than others with respect to negative events. This result warrants further study.

What is of interest, and merits further study in the Bahamian context, is that it appears that the negative aspects of the respondents' sexual initiation appear to be detectable today through their mental health score, a finding consistent with Dovran et al. (2016) and Burgić Radmanović (2020). This suggests that a person's early sexual experience can have life-long consequences. This would suggest that every effort should be made to ensure that a person is appropriately prepared for engaging in sexual intercourse, even if the act is consensual, or how a participant might protect themselves from abuse, if it is not consensual. This may mean that additional efforts need to be made with respect to sex education for school children due to the fact that some $25 \%$ of female respondents' first experience was during their school years, and, for females in particular, this experience would most certainly be classified legally as rape (Table 4).

As others have indicated, victims who fail to seek help from such a traumatic event may find that their mental health problems becoming worse (Tansill et al., 2012). These negative impacts can also affect the children 
of sexually abused mothers, as they are less likely to praise their children, i.e., use positive parenting techniques (Fujiwara et al., 2012).

Although most participants were more positive about their most recent sexual experience, those who felt abused or raped had higher mental health scores than those who had not experienced this trauma. Although the study methodology does not allow for national estimates of the occurrence of sexual abuse or rape to be made, the fact that study participants reported having sexual intercourse against their will in the previous four weeks starts to give an idea of the possible frequency of sexual abuse or rape. There was also an indication that persons who were not "straight" in their sexual behaviour had higher mental scores, a result consistent with Szalacha et al. (2017), who also found differences in the mental health of females who reported having sex with other females. In Portugal, the stigma of being nonheterosexual has been associated with elevated mental health concerns (Pereira \& Costa, 2016). These observations reflect in part the stigma of being what is loosely termed "gay" or not engaging solely in heterosexual sex ("The Truth About Being Gay," 2016), a stigma that has resulted in persons being attacked in the streets (Turnquest, 2016). Consequently, this marginalized group may be in even greater need of mental health care than the heterosexual group.

Overall, the results from this study demonstrate the link between negative sexual encounters and mental health and its longterm nature in the Bahamian context. Consequently, the recommendations of Naylor et al. (2012), which focus on integrating mental health care with primary health care, may be beneficial. The authors hope that these results will assist with increasing the awareness of the hidden harm of sexual trauma and encourage society to sensitively engage victims of negative sexual experiences.

\section{Acknowledgments}

We would like to acknowledge the students in Nursing Research 409 Spring 2020 class, which was taught by Dr. Elizabeth Williams, who participated in the data collection and shared their final papers with us. Dr. Williams died before she could write up this investigation, so we have had the honour of writing this paper on her behalf and have attempted to present the data in a way consistent with her IRB submission. We are grateful for the feedback of Dr. Michelle Bettin on an earlier draft and for the comments of the referees.

Dr. Williams died on November 26, 2020, aged 55. 


\section{References}

Ali, T. S., Mogren, I., \& Krantz, G. (2013). Intimate partner violence and mental health effects: A population-based study among married women in Karachi, Pakistan. International Journal of Behavioral Medicine, 20(1), 131-139. https://doi.org/10.1007/s12529-011-92016

Amirkhan, J. H. (1990). A factor analytically derived measure of coping: The Coping Strategy Indicator. Journal of Personality and Social Psychology, 59(5), 1066-1074. https://doi.org/ 10.1037/00223514.59.5.1066

Aranha, S. B. (2016). Sexual abuse: The secret needing to be told. In Violence in The Bahamas: A Monograph on Research Undertaken by the College of The Bahamas on Violence in The Bahamas (pp. 87-92). College of The Bahamas. https://ufdc.ufl.edu/AA00078778/00008

Bahamas National Task Force for GenderBased Violence. (2015). Strategic plan to address gender-based violence. Ministry of Social Services and Community Development. https://bit.ly/31mK5LL

Barton, E. N. (2012). Mental health [Editorial]. The West Indian Medical Journal, 61(5), 473-474. https://www.mona.uwi.edu/fms/wimj/syst em/files/article_pdfs/en_barton.qxd_0.pd $\mathrm{f}$

Benjamin, L., \& LeGrand, C. (2012). Sound and fury: Newspaper coverage of the marital rape debate in New Providence. International Journal of Bahamian Studies, 18, 16-35. https://doi.org/10.15362/ijbs.v18i0.164

Bergen, R. K., \& Barnhill, E. (2006). Marital rape: New research and directions.
National Resource Center on Domestic Violence, Pennsylvania Coalition Against Domestic Violence. http://www.ncdsv.org/images/VAWnet_ MaritalRapeNewResearchDirections_22006.pdf

Bethel, N., \& Fielding, W. J. (2020). Attitudes and knowledge of Bahamian college students regarding sexual consent. International Journal of Bahamian Studies, 26, 73-100. https://doi.org/10.15362/ijbs.v26i0.371

Brooks, G. R. (2001). Masculinity and men's mental health. Journal of American College Health, 49(6), 285-297. https://doi.org/10.1080/074484801095963 15

Burgić Radmanović, M. (2020). Mental disorders in sexually abused children. Psychiatria Danubina, 32(Suppl 3), 349352. http://www.psychiatriadanubina.com/UserDocsImages/pdf/dnb_ vol32_noSuppl\%203/dnb_vol32_noSuppl \%203_349.pdf

Burnett-Garraway, C. H. (2001). Domestic violence: A study of the occurrence and predictors in an Accident and Emergency Department, The Bahamas [Unpublished doctoral dissertation, University of the West Indies, Cave Hill, Barbados]. https://www.dloc.com/AA00008697/0000 1

Campbell, J. C. (2002). Health consequences of intimate partner violence. The Lancet, 359(9314), 1331-1336. https://doi.org/10.1016/S01406736(02)08336-8

Deveaux, L., \& Rolle, G. (2016). The focus on youth prevention and education research programme. International 
Journal of Bahamian Studies, 22, 91-98. https://doi.org/10.15362/ijbs.v22i0.276

Dovran, A., Winje, D., Øverland, S., Arefjord, K., Hansen, A., \& Waage, L. (2016). Childhood maltreatment and adult mental health. Nordic Journal of Psychiatry, 70(2), 140-145. https://doi.org/10.3109/08039488.2015.10 62142

Fujiwara, T., Okuyama, M., \& Izumi, M. (2012). The impact of childhood abuse history, domestic violence and mental health symptoms on parenting behaviour among mothers in Japan. Child: Care, Health and Development, 38(4), 530-537. https://doi.org/10.1111/j.13652214.2011.01272.x

Hailes, H. P., Yu, R., Danese, A., \& Fazel, S. (2019). Long-term outcomes of childhood sexual abuse: An umbrella review. The Lancet Psychiatry, 6(10), 830-839. https://doi.org/10.1016/S22150366(19)30286-X

Hébert, M., Lavoie, F., Vitaro, F., McDuff, P., \& Tremblay, R. E. (2008). Association of child sexual abuse and dating victimization with mental health disorder in a sample of adolescent girls. Journal of Traumatic Stress, 21(2), 181-189. https://doi.org/10.1002/jts.20314

Musevenzi, J., \& Musevenzi, M. (2018). The lived experiences of male survivors: The case of adult rape clinic at Parirenyatwa Hospital, Harare. Journal of Gleanings from Academic Outliers, 7(1), 1-24.

Naylor, C., Parsonage, M., McDaid, D., Knapp, M., Fossey, M., \& Galea, A. (2012). Long-term conditions and mental health: The cost of co-morbidities. The King's Fund. https://www.kingsfund.org.uk/sites/defaul t/files/field/field_publication_file/longterm-conditions-mental-health-costcomorbidities-naylor-feb12.pdf

Nickerson, A., Steenkamp, M., Aerka, I. M., Salters-Pedneault, K., Carper, T. L., Barnes, J. B., \& Litz, B. T. (2013). Prospective investigation of mental health following sexual assault. Depression and Anxiety, 30(5), 444-450. https://doi.org/10.1002/da.22023

Pereira, H., \& Costa, P. A. (2016). Modeling the impact of social discrimination on the physical and mental health of Portuguese gay, lesbian and bisexual people. Innovation: The European Journal of Social Science Research, 29(2), 205-217. https://doi.org/10.1080/13511610.2016.11 57683

Pilgrim, N. A., \& Blum, R. W. (2012). Adolescent mental and physical health in the English-speaking Caribbean. Panamerican Journal of Public Health = Revista Panamericana de Salud Pública, 32, 62-69. https://doi.org/10.1590/S102049892012000700010

Potter, S. J., Fox, N., Smith, D., Draper, N., Moschella, E. A., \& Moynihan, M. M. (2020). Sexual assault prevalence and community college students: Challenges and promising practices. Health Education \& Behavior, 47(1S), 7S-16S. https://journals.sagepub.com/doi/full/10.1 177/1090198120910988

Rees, D. I., \& Sabia, J. J. (2013). Forced intercourse, mental health, and human capital. Southern Economic Journal, 80(2), 324-344. https://doi.org/10.4284/0038-40382013.015

Rolle, R. (2020, November 3). UB students sex assaults shock: Campus survey reveals 
one-in-three are victim of some form of rape: Comments. The Tribune.

http://www.tribune242.com/news/2020/no v/03/ub-students-sex-assaults-shockcampus-survey-revea/

Royal Bahamas Police Force. (2020). 2019 crime statistics.

http://www.royalbahamaspolice.org/statist ics/crime_stats2019.pdf

Sharma, S. (2018). Impact of childhood sexual abuse on female sexuality. SIS Journal of Projective Psychology \& Mental Health, 25(2), 173-177. http://search.ebscohost.com.cob.idm.oclc. org/login. aspx ?direct $=$ true $\& d b=a 9 h \& A N$ $=133726493 \&$ site $=$ ehost-live.

Smith, L., Jacob, L., López-Sánchez, G. F., Grabovac, I., Yang, L., Pizzol, D., Sigman, A., McDermott, D., \& Koyanagi, A. (2020). A multicountry study of the violence-related risk factors for early sexual debut and risky sexual behavior in adolescents. Journal of Interpersonal Violence, https://doi.org/10.1177/088626052092750 2

Swahnberg, I. K., \& Wijma, B. (2003). The NorVold Abuse Questionnaire (NorAQ): Validation of new measures of emotional, physical, and sexual abuse, and abuse in the health care system among women. The European Journal of Public Health, 13(4), 361-366.

https://doi.org/10.1093/eurpub/13.4.361

Szalacha, L. A., Hughes, T. L., McNair, R., \& Loxton, D. (2017). Mental health, sexual identity, and interpersonal violence: Findings from the Australian longitudinal women's health study. BMC Women's Health, 17(1), 94. https://doi.org/10.1186/s12905-017-04525
Tansill, E. C., Edwards, K. M., Kearns, M. C., Gidycz, C. A., \& Calhoun, K. S. (2012). The mediating role of trauma-related symptoms in the relationship between sexual victimization and physical health symptomatology in undergraduate women. Journal of Traumatic Stress, 25(1), 79-85. https://doi.org/10.1002/jts.21666

Thoresen, S., Myhre, M., Wentzel-Larsen, T., Aakvaag, H. F., \& Hjemdal, O. K. (2015). Violence against children, later victimisation, and mental health: A crosssectional study of the general Norwegian population. European Journal of Psychotraumatology, 6(1), 26259. https://doi.org/10.3402/ejpt.v6.26259

The truth about being gay [Letter to the editor]. (2016, February 12). The Tribune. http://www.tribune242.com/news/2016/fe b/12/truth-about-being-gay/

Turnquest, A. (2016, May 14). Video: Investigation urged over 'homophobic attack.' The Tribune.

http://www.tribune242.com/news/2016/m ay/09/investigation-urged-overhomophobic-attack/

Voth Schrag, R. J., \& Edmond, T. E. (2018). Intimate partner violence, trauma, and mental health need among female community college students. Journal of American College Health, 66(7), 702711. https://doi.org/10.1080/07448481.2018.14 56443

World Health Organization. (2017). Mental health atlas 2017. Member state profile. The Bahamas. https://www.who.int/mental_health/evide nce/atlas/profiles-2017/BHS.pdf?ua= 